Research Paper:

\title{
The Effectiveness of Group Schema Therapy on Adjusting the Early Maladaptive Schemas of the Drug-Dependent Women
}

\author{
Shahram Tirandaz ${ }^{1}$, Bahman Akbari ${ }^{{ }^{*}}$
}

1. Department of Psychology, Rasht Branch, Islamic Azad University, Rasht, Iran.

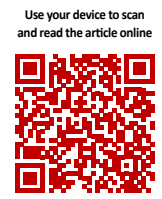

Citation Tirandaz Sh, Akbari B. The Effectiveness of Group Schema Therapy on Adjusting the Early Maladaptive Schemas of the Drug-Dependent Women. Avicenna J of Neuropsychophysiology. 2018; 5(3):123-130. http://dx.doi.org/10.32598/ajnpp.5.3.123

http://dx.doi.org/10.32598/ajnpp.5.3.123

(C) 0

Article info:

Received: 27 Jan 2018

Accepted: 05 Jun 2018

Available Online: 01 Aug 2018

Keywords:

Female, Psychotherapy,

Substance-related disorders

\begin{abstract}
AB STRACT
Introduction: Drug addiction treatment may be associated with more challenges and problems in women compared with men.

Objectives: The present research aimed at determining the impact of group schema therapy on adjusting the early maladaptive schemas in drug-dependent women.

Materials and Methods: The present research was an experimental study with a pretest-posttest design and a control group. The statistical population included all of the women with substance abuse disorder who referred to the addiction recovery centers in Rasht from November to December 2019. Using a randomized sampling, 60 individuals were selected and assigned into the experimental and control groups ( $n=30$ for each group) and completed the Young Schema Questionnaire - Short Form Version 3 (YSQ-S3). The experimental group was subjected to the schema therapy, whereas the control group did not receive any intervention. The data were analyzed using a one-way Analysis of Covariance (ANCOVA) and Multivariate Analysis of Covariance (MANCOVA) by SPSS V. 22 software.
\end{abstract}

Results: The results showed that group schema therapy decreased early maladaptive schemas, including disconnection and rejection $(P<0.01)$, self-control and impaired performance $(P<0.01)$, impaired limits $(P<0.003)$, and over vigilance and inhibition $(P<0.001)$.

Conclusion: Based on the results, schema therapy reduced the dimensions of early maladaptive schemas, such as disconnection and rejection, self-control and impaired performance, impaired limits, and over vigilance and inhibition in drug-dependent women, however it did not decrease the other-directness dimension.

\section{* Corresponding Author:}

Bahman Akbari, PhD.

Address: Department of Psychology, Rasht Branch, Islamic Azad University, Rasht, Iran

Tel: +98 (911) 1361102

E-mail: akbari@iaurasht.ac.ir 


\section{Introduction}

rug addiction and drug abuse are one of the most significant global crises that threaten the health, well-being, political stability, and economic and social structure of different countries [1]. Drug abuse and dependence are a recurring and chronic phenomenon affecting all aspects of an individual's life, and regardless of their risks and consequences the victims of substance abuse are increasing [2]. Regarding the prevalence of addiction, a national survey has estimated that about $7.7 \%$ of men vs. $5 \%$ of women use narcotics [3]. Taking painkillers, tranquilizers, and stimulants for non-medical use in women is equal or more often than that of men [4].

As soon as women start drug abuse, they show their tendency to addiction more than men do, and they also experience negative consequences (from a medical point of view) earlier than men. Also, the factors that increase the risk of addiction in women and men are different. Furthermore, regarding treatment hindrances, women may have more problems than men [5]. During substance abuse treatment, women in comparison with men are less likely to respond to medications and psychotherapy (due to their monthly period) [6].

The incidence of early maladaptive schemas in addicts has attracted many researchers to find a method to develop their treatment [7]. Maladaptive schemas are one of the underlying mechanisms in fabricating inefficient behaviors. These schemas are the self-inflicting emotional and cognitive patterns in an individual, which are formed in mind due to the lack of satisfaction with emotional needs at the beginning of their development and repeat through life. The early maladaptive schemas in the deepest level of cognition often act outside the level of consciousness and psychologically make the individual susceptible to develop disorders, such as depression, anxiety, ineffective communication, addiction, behavioral disorders, anti-social behaviors, and psychosocial disorders [8].

In recent years, increasing attention has been paid to the recognition and introduction of cognitive processes. One of the cognitive factors affecting addiction is the scope of schemas, which needs to be considered [9]. It is assumed that drug use is one of the handling strategies used to avoid the adverse effects of spontaneous maladaptive schemas [10].

The schema therapy developed by Young et al. is a modern and integrated treatment based on the devel- opment of concepts and methods of standard cognitive-behavioral therapy [11]. The schema therapy has combined the principles and foundations of cognitivebehavioral therapy, object relations in Gestalt Therapy, constructivism, and psychoanalysis as a valuable therapeutic and conceptual model. The results of Khosravani et al. study [12] showed that schema therapy was effective in improving the early maladaptive schemas of individuals with substance abuse. Also, the results of Shorey et al. study [13] indicated the effect of schema therapy on early maladaptive schemas in addicted individuals.

Early maladaptive schemas may underlie the development and maintenance of substance abuse, as both are chronic and enduring health problems. Moreover, Ball postulated that substance use may be a mechanism, by which individuals attempt to avoid the negative beliefs as well as feelings associated with early maladaptive schemas. Ball further discussed the relevance of treating early maladaptive schemas among substance users and even developed a manualized therapy by combination of the aspects of relapse prevention and schema therapy, called as "Dual-Focused Schema Therapy (DFST)". It has demonstrated that substance use disorder treatment that concurrently focuses on targeting and modifying early maladaptive schemas, namely DFST, results in improved outcomes compared with traditional 12-step therapy [14].

To our knowledge, no study has been done on the effectiveness schema therapy on early maladaptive schemas among young substance-abusing women. Thus, the current study was done to assess the effectiveness of schema therapy among young adult women. The lack of considering gender differences in addiction and its related issues and also the lack or absence of studies on women and addiction indicate the importance of conducting more investigations in this realm. It is also necessary to consider the cultural and social differences and consequently the behavioral differences. Although men have more access to drugs than women, the increased chance of access to drugs has recently also shown in women. Accordingly, the probability of experiencing drug use in women is also rapidly increasing, which implies the necessity of conducting the current research. In this regard, this study aimed at determining the effectiveness of group schema therapy on adjusting the early maladaptive schemas in women with substance abuse. 
Table 1. Explanation of the schema-based cognitive therapy sessions

\begin{tabular}{|c|c|}
\hline Session & Purpose \\
\hline First & Familiarizing the group members with each other and introducing and expressing the rules governing meetings \\
\hline Second & Recognizing the mood, physiological and emotional states \\
\hline Third & Understanding your issues and the five main dimensions of life \\
\hline Fourth & $\begin{array}{l}\text { Focusing on the present and also your behaviors with an emphasis on meditative and regular desensitization } \\
\text { methods }\end{array}$ \\
\hline Fifth & Understanding personal goals, values, and beliefs and reconstructing mental schemas \\
\hline Sixth & Training techniques to reduce and eliminate maladaptive schemas \\
\hline Seventh & $\begin{array}{l}\text { Responsibility regarding the results of previous misconceptions through training of the past sessions and acquiring } \\
\text { a new successful identity }\end{array}$ \\
\hline Eight & Summing up sessions \\
\hline
\end{tabular}

\section{Materials and Methods}

The present research was a semi-experimental study with pre-test and post-test design and a control group. The statistical population included all substance-abusing women referred to drug recovery centers in Rasht during November to December 2019. Sampling was done using a randomized sampling method. Based on the effect size of 0.25 , an alpha coefficient of 0.05 and the power of 80.0 in both groups, the sample size needed to achieve desired levels of power was determined 30 individuals in each group [15]. Thus, in the first stage, Rasht city was divided into five districts, including the north, south, east, west and central districts. In the second stage, two addiction recovery centers were randomly selected from each district, and all women drug users referring to these centers (10 centers) were selected based on the inclusion and exclusion criteria of the research.

They were subjected to complete the Young Schema Questionnaire - Short Form Version 3 (YSQ-S3). The scores of 60 subjects were one standard deviation higher than the mean of 270 and were randomly assigned into two groups of 30 each. The completed questionnaires were considered as a pre-test for these two groups and then the experimental group was exposed to group schema therapy for 8 ninety-minute sessions every week for two sessions and one and a half months between November to mid-December 2019. The sessions were conducted in the addiction recovery center affiliated to the Central Welfare Organization.
The control group received only their routine medical care. One week after the group schema therapy, a posttest of the first maladaptive schemas was performed. The inclusion criteria were female gender, reading and writing literacy, lack of psychological and behavioral problems other than drug abuse, and obtaining a significantly higher score in the early maladaptive schemas and psychological adaptation. The exclusion criteria were being absent for two sessions or more in the intervention program and incomplete completion of the questionnaires. Schematic-based cognitive therapy sessions are described in Table 1.

The subjects were informed about the research and voluntary participation, as well. Participants were assured of the confidentiality of their information and using them only for research purposes. They also were informed that their names and surnames were not recorded in order to observe ethical considerations.

Young Schema Questionnaire - short form version 3 (YSQ-S3)

YSQ consists of 90 items and 18 schemas in 5 dimensions and areas, including disconnection and rejection, self-control and impaired performance, impaired limits, other-directedness, over vigilance, and inhibition. It is scored on a Likert scale ranging from completely false (1) to entirely correct (6) [16]. To obtain the total score of each sub-scale with the inefficient schema, the mean score of the five dimensions was calculated. When the average score of an individual in each subscale is higher 
than 15 , or he/she chooses the options 5 or 6 in three questions out of five questions regarding each schema, she/he has that schema.

The higher scores are indicative of a stronger presence of the maladaptive schema. The results showed that for each early maladaptive schema, the Cronbach's alpha coefficient ranged from 0.83 (enmeshment/undeveloped self schema) to 0.96 (defectiveness/shame schema), and also the test-retest coefficient in the nonclinical population was between 0.05 and 0.82 [17]. The standardization of this questionnaire in Iran was done by using on 387 university students in Tehran and its internal consistency (by a Cronbach's alpha reliability coefficient) was obtained 0.97 in females and 0.98 in males. The YSQ reliability was 0.93 , and the failure subscale showed the highest $(0.92)$ reliability $(P<0.05)$. The validity and reliability of this questionnaire were 0.72 and 0.86 , respectively.

Descriptive statistics, such as frequency, Mean $\pm S D$, and also the coefficient of Skewness and Kurtosis were used to study the normality of the data as well as inferential statistics by observing the required assumptions. The total score of the questionnaire was assessed by One-way Analysis of Covariance (ANCOVA) and the subscales were analyzed via Multivariate Analysis Covariance (MANCOVA) using SPSS V. 22 Software.

\section{Results}

The demographic characteristics of the participants showed that 10 subjects (16.7\%) were in the age range of 20 to 25 years old, 14 subjects (23.3\%) were 26 to 30 years old, 26 cases (43.3\%) were 31 to 35 years old, and 10 subjects (16.7\%) were 20 to 25 years old. The results showed that the mean score of disconnection and rejection in the experimental group declined from $80.5 \pm 25.3$ in the pre-test to $67.3 \pm 18.1$ in the post-test $(\mathrm{P}<0.001)$. The mean score of self-control and impaired performance of the experimental group decreased from
$67.3 \pm 22.9$ in the pretest to $57.5 \pm 17.7$ in the post-test $(P<0.001)$, and that of the impaired limits in the experimental group decreased from $36.6 \pm 13.1$ in the pre-test to $26.9 \pm 9.1$ in the post-test $(P<0.001)$.

In addition, the mean score of the over vigilance and inhibition in test group declined from $62.5 \pm 18.5$ in pre-test to $55.3 \pm 17.2$ in post-test $(P<0.001)$, whereas the mean score of the other-directedness in the experimental group decreased from $54.7 \pm 17.1$ in the pre-test to $52.1 \pm 16.5$ in post-test, which was not statistically significant.

The mean score of the components of maladaptive schemas in the pre-test and post-test did not show a significant difference. To assess the normal distribution of variables among the subjects and the Skewness and Kurtosis of between +2 and -2 , parametric tests, such as ANCOVA and MANCOVA can be used to investigate research hypotheses. Also, linear regression's F-statistics of the relationship between pre-test and post-test scores for all variables were significant at the level of 0.001 . Accordibgly, it can be concluded that there was a linear relationship between pre-test and post-test scores of early maladaptive schemas and their dimensions.

To determine the effect size of independent variables (group schema therapy) on the dimensions of early maladaptive schemas (disconnection and rejection, self-control and impaired performance, impaired limits, other-directness, over vigilance, and inhibition), the MANCOVA was used. To this end, the implications of using this test were examined. First, the homogeneity of the slope of the regression line was investigated, which showed that the interaction between the conditions and the pre-test was not significant $(P<0.19, F=4.27)$. As a result, the results confirmed the homogeneity of the regression slope. The Levine's test was used to evaluate the variance of dependent variables.

Based on the results, the homogeneity of errors between both groups was confirmed for dependent vari-

Table 2. Results of Multivariate Covariance Analysis (MANCOVA) of the dimensions of early maladaptive schemas in the control and experimental group

\begin{tabular}{cccccc}
\hline Test & Values & F & d.f1 & d.f1 & P \\
\hline Pillai's Trace & 0.812 & & & & \\
Wilks' lambda & 0.188 & 11.244 & 5 & & 0.001 \\
Hotelling's Trace & 4.325 & & & \\
Roy's Largest Root & 4.325 & & & \\
\hline
\end{tabular}


Table 3. Effects of the items of the dimensions of early maladaptive schemas after adjusting for pre-test and post-test scores using multivariate variance analysis in the experimental and control groups

\begin{tabular}{cccccc}
\hline Variables & $\begin{array}{c}\text { Sum of } \\
\text { Suares }\end{array}$ & $\begin{array}{c}\text { Degree of } \\
\text { Freedom }\end{array}$ & $\begin{array}{c}\text { Mean } \\
\text { Squares }\end{array}$ & F & Beta \\
\hline $\begin{array}{c}\text { Disconnection \& rejection } \\
\begin{array}{c}\text { Self-control \& } \\
\text { impaired performance }\end{array}\end{array}$ & 176.591 & 1 & 176.591 & 7.837 & 0.012 \\
\hline $\begin{array}{c}\text { Impaired limits } \\
\text { Overvigilance \& inhibition }\end{array}$ & 155.577 & 1 & 155.577 & 6.777 & 0.019 \\
\hline
\end{tabular}

AJNPP

Table 4. Final Estimated Means of Dimensions of Early Maladaptive Schemas

\begin{tabular}{|c|c|c|c|c|c|}
\hline Variable & Group & Mean & Mean Difference & Standard Error & $\mathbf{P}$ \\
\hline $\begin{array}{l}\text { Disconnection \& } \\
\text { rejection }\end{array}$ & $\begin{array}{c}\text { Experimental } \\
\text { Control }\end{array}$ & $\begin{array}{l}58.881 \\
65.952\end{array}$ & -7.071 & 2.526 & 0.012 \\
\hline $\begin{array}{c}\text { Self-control \& } \\
\text { impaired performance }\end{array}$ & $\begin{array}{c}\text { Experimental } \\
\text { Control }\end{array}$ & $\begin{array}{l}47.223 \\
53.860\end{array}$ & -6.637 & 2.550 & 0.019 \\
\hline Impaired limits & $\begin{array}{c}\text { Experimental } \\
\text { Control }\end{array}$ & $\begin{array}{l}23.336 \\
29.414\end{array}$ & -6.078 & 1.794 & 0.003 \\
\hline $\begin{array}{l}\text { Overvigilance \& } \\
\text { inhibition }\end{array}$ & $\begin{array}{c}\text { Experimental } \\
\text { Control }\end{array}$ & $\begin{array}{l}54.710 \\
60.290\end{array}$ & -5.579 & 0.816 & 0.001 \\
\hline
\end{tabular}

ables $(\mathrm{P}<0.05)$. In addition, in order to investigate the covariance matrix of dependent variables, the Box's M test was used in the experimental and control groups. The $F$ statistic of the Box's M test (0.0537) was not significant $(F=0.537, P<921)$. Therefore, it can be concluded that the covariance matrix of the dependent variables was equal in both groups. Also, to investigate sphericity or the significance of the relationship between the dimensions of the early maladaptive schemas, the Bartlett's Chi-square test was used. Bartlett's chi-square test to examine the significance of the correlation between the dimensions of the early maladaptive schemas was $53.4 \%$, which was significant at the level of 0.001 . Therefore, there was a significant relationship between these dimensions. Accordingly, MANCOVA was used.

According to Table 2, multivariate F-statistic regarding the difference between the experimental and control groups in the dimensions of the early maladaptive schemas (disconnection and rejection, self-control and impaired performance, impaired limits, other-directedness, and over vigilance and inhibition) was significant at the level of 0.001 (Wilks' Lambda $=0.188, F=11.244$, $\mathrm{P}<0.001)$. Therefore, it can be concluded that there was a significant difference between the experimental and control groups at least in one of the dimensions of the early maladaptive schemas in the post-test after adjusting for the pre-test scores and the interaction between the dimensions of the early maladaptive schemas. Table 3 presented the effects of the items of the dimensions of the early maladaptive schemas.

As shown in Table 3, results of the tests of betweensubjects effects showed that the impact of group schema therapy on modification of the dimensions of the early maladaptive schemas, including disconnection and rejections $(F=7.837, d f=1, P<0.012)$, self-control and impaired performance $(F=6.777, d f=1, P<0.019)$, impaired limits ( $F=11.476, d f=1, P<0.003)$ and over vigilance $(F=46.743, d f=1, P<0.001)$, after adjusting for of pre-test scores was significant. This means that these dimensions in the experimental group in the post-test were less than those of the control group. In order to investigate the lower scores of dimensions of the early 
maladaptive schemas in the post-test between groups, the corrected averages are reported in Table 4.It should be noted that the Bonferroni correction method was used to estimate the mean scores.

According to Table 4, there was a statistically significant difference between the experiment and control groups regarding the dimensions, including disconnection and rejection (-7.07), self-control and impaired performance (-6.63), impaired limits $(-6.07)$, over vigilance and inhibition $(-5.57)(\mathrm{P}<0.001)$. Therefore, it can be said that the mean of the experimental group in these dimensions was significantly lower than the control group. In this regard, it can be concluded that using group schema therapy affects the dimensions, such as disconnection and rejection, self-control and impaired performance, impaired limits, and over vigilance and inhibition schemes in drug-dependent women and also reduces the maladaptive schemas among them.

\section{Discussion}

This study showed that after group schema therapy, the mean of disconnection and rejection in the experimental group decreased from $80.5 \pm 25.3$ in the pre-test to $67.3 \pm 18.1$ in the post-test, self-control and impaired performance declined from $67.3 \pm 22.9$ to $57.5 \pm 17.7$ in, impaired limits decreased from $35.6 \pm 13.1$ to $26.9 \pm 1 / 9$, and over vigilance and inhibition decreased from $62.5 \pm 18.5$ to $55.3 \pm 17.2$ ) in the post-test. In addition, other-directedness in the experimental group decreased from $54.7 \pm 17.1$ in the pre-test to $52.1 \pm 16.5$ in the post-test, which was not statistically significant. The mean of the components of maladaptive schemas in the pre-test and post-test did not show a significant difference. These findings are in line with the results of Khosravani et al. [12] regarding the effect of schema therapy on improving the early maladaptive schemas in individuals dependent on drugs, and also Shorey et al. research [13], on the effect of schema therapy on the early maladaptive schemas in addicted individuals under treatment in Shiraz hospitals.

In explaining this finding, it can be said that schemas are in-depth and comprehensive patterns, or themes that are formed from memories, emotions, cognitive phenomena, and body feelings during childhood and adolescence and will be continued in next stages of life. According to Young, as the schema therapy emphasizes on the deepest level of cognition, it seeks to correct the core problem, which is highly effective in the treatment of mental disorders and preventing their recurrence. Schema therapy is a new and integrated treatment that provides a systematic program for evaluating and modifying early maladaptive schemas.

It is based on classical cognitive-behavioral therapy and uses cognitive, behavioral, interpersonal, attachment, and empirical techniques for evaluation and modification of schemas and uses stimulating techniques and the concept of coping styles [18].

The schema therapy puts more emphasis on the relation therapy, emotional experience, and discussion of early life experiences, which is based on the early maladaptive schemas [19]. Young believed that the schema is superior to other short-term therapies for the treatment of severe and chronic psychiatric disorders, such as personality disorders, depression, and chronic anxiety, drug abuse, etc. Scheme-focused therapy combines cognitive, behavioral, interpersonal, and experimental techniques to evaluate schemas, and focuses on the childhood backgrounds and developmental processes involved in the emergence and maintenance of these schemas [20].

Accordingly, schema therapy by organizing the cognitions and modifying the underlying schemas of those with substance dependence neutralizes the damages caused by these maladaptive schemas to an acceptable level, and this process results in the increased personal insight to improve the causes of the problem. Therefore, schema therapy is effective in modifying the early maladaptive schemas of women with substance abuse.

The limitations of this study included the lack of controlling the duration and severity of addiction, the type of drugs consumed by the subjects, the socioeconomic status of the participants, and also the lack of a followup period to examine durability of the treatment over time due to executive problems. Due to the impossibility of controlling the duration and severity of addiction and also the type of drug used by addicted individuals in the present study, it is suggested to control these factors in the future studies. it is also recommended to monitor the socioeconomic status of the subjects and consider a follow-up period in future studies to investigate the effect of treatment over time.

This study showed that the schema therapy reduced the components of early maladaptive schemas, including disconnection and rejection, self-control and impaired performance, impaired limits, and over vigilance and inhibition in drug-dependent women, but it did not reduce other-directness component. This result for the first time showed the efficacy of schema therapy on 
early maladaptive schemas in women with substance abuse. It is suggested that group schema therapy must be the priority of clinical interventions in order to reduce the early maladaptive schemas in women suffering from drug abuse.

\section{Ethical Considerations}

\section{Compliance with ethical guidelines}

All ethical principles were considered in this research. The participants were informed about the purpose of the research and its stages and signed the informed consent. They were also assured of the confidentiality of their information. Moreover, The subjects were allowed to withdraw from the study whenever they wish. They also were provided with the results of the research.

\section{Funding}

This research did not receive any specific grant from funding agencies in the public, commercial, or not-forprofit sectors.

\section{Authors' contributions}

All authors contributed equally in preparing all parts of the research.Conflict of interest

The authors declare no conflict of interests.

\section{References}

[1] Franklin G, Sabel J, Jones CM, Mai J, Baumgartner C, Banta-Green $\mathrm{CJ}$, et al. A comprehensive approach to address the prescription opioid epidemic in Washington State: Milestones and lessons learned. American Journal of Public Health. 2015; 105(3):463-9. [DOI:10.2105/AJPH.2014.302367] [PMID] [PMCID]

[2] Zgierska A, Miller M, Rabago D. Patient satisfaction, prescription drug abuse, and potential unintended consequences. JAMA. 2012; 307(13):1377-8. [DOI:10.1001/jama.2012.419] [PMID] [PMCID]

[3] Tantirangsee N, Assanangkornchai S, Marsden J. Effects of a brief intervention for substance use on tobacco smoking and family relationship functioning in schizophrenia and related psychoses: A randomised controlled trial. Journal of Substance Abuse Treatment. 2015; 51:30-7. [DOI:10.1016/j.jsat.2014.10.011] [PMID]

[4] Kendler KS, Sundquist K, Ohlsson H, Palmúr K, Maes H, Winkleby $\mathrm{MA}$, et al. Genetic and familial environmental influences on the risk for drug abuse: a national Swedish adoption study. Archives of General Psychiatry. 2012; 69(7):690-7. [DOI:10.1001/archgenpsychiatry.2011.2112
[5] Roy S, Ninkovic J, Banerjee S, Charboneau RG, Das S, Dutta R, et al. Opioid drug abuse and modulation of immune function: Consequences in the susceptibility to opportunistic infections. Journal of Neuroimmune Pharmacology. 2011; 6(4):442-65. [DOI:10.1007/ s11481-011-9292-5] [PMID] [PMCID]

[6] Dart RC, Surratt HL, Cicero TJ, Parrino MW, Severtson SG, BucherBartelson B, et al. Trends in opioid analgesic abuse and mortality in the United States. The New England Journal of Medicine. 2015; 372(3):241-8. [DOI:10.1056/NEJMsa1406143] [PMID]

[7] Shorey RC, Stuart GL, Anderson S. The early maladaptive schemas of an opioid-dependent sample of treatment-seeking young adults: A descriptive investigation. Journal of Substance Abuse Treatment 2012; 42(3):271-8. [DOI:10.1016/j.jsat.2011.08.004] [PMID] [PMCID]

[8] Shorey RC, Stuart GL, Anderson S. Early maladaptive schemas among young adult male substance abusers: A comparison with a non-clinical group. Journal of Substance Abuse Treatment. 2013, 44(5):522-7. [DOI:10.1016/j.jsat.2012.12.001] [PMID] [PMCID]

[9] Shorey RC, Stuart GL, Anderson S. Differences in early maladaptive schemas between a sample of young adult female substance abusers and a non-clinical comparison group. Clinical Psychology \& Psychotherapy. 2014; 21(1):21-8. [DOI:10.1002/cpp.1803] [PMID] [PMCID]

[10] Renner F, van Goor M, Huibers M, Arntz A, Butz B, Bernstein D Short-term group schema cognitive-behavioral therapy for young adults with personality disorders and personality disorder features: associations with changes in symptomatic distress, schemas, schema modes, and coping styles. Behaviour Research and Therapy. 2013; 51(8):487-92. [DOI:10.1016/j.brat.2013.05.011] [PMID]

[11] Bakhshi Bojed F, Nikmanesh Z. Role of early maladaptive schemas on addiction potential in youth. International Journal of High Risk Behaviors \& Addiction. 2013; 2(2):72-6. [DOI:10.5812/ijhrba.10148] [PMID] [PMCID]

[12] Khosravani V, Alvani A, Seidisarouei M. The relation of early maladaptive schemas and behavioral inhibition/approach systems to defense styles in abusers of the synthetic drug: A cross-sectional study. Journal of Substance Use. 2016; 21(6):652-61. [DOI:10.3109/ 14659891.2015.1130184]

[13] Shorey RC, Brasfield H, Anderson S, Stuart GL. The relation be tween trait mindfulness and early maladaptive schemas in men seeking substance use treatment. Mindfulness. 2015; 6(2):348-55. [DOI:10.1007/s12671-013-0268-9] [PMID] [PMCID]

[14] Hawke LD, Provencher MD. The Canadian French Young Schema Questionnaire: Confirmatory factor analysis and validation in clinical and nonclinical samples. Canadian Journal of Behavioural Science/Revue canadienne des sciences du comportement. 2012 44(1):40-9. [DOI:10.1037/a0026197]

[15] Esmaeilian N, Dehghani M, Koster EHW, Hoorelbeke K. Early maladaptive schemas and borderline personality disorder features in a nonclinical sample: A network analysis. Clinical Psychology \& Psychotherapy. 2019; 26(3):388-98. [DOI:10.1002/cpp.2360] [PMID]

[16] Lee SJ, Choi YH, Rim HD, Won SH, Lee DW. Reliability and validity of the Korean Young Schema Questionnaire-Short Form-3 in medical students. Psychiatry Investigation. 2015; 12(3):295-304. [DOI:10.4306/pi.2015.12.3.295] [PMID] [PMCID]

[17] Shorey RC, Anderson SE, Stuart GL. Gender differences in early maladaptive schemas in a treatment-seeking sample of alcoholdependent adults. Substance Use \& Misuse. 2012; 47(1):108-16. [D OI:10.3109/10826084.2011.629706] [PMID] [PMCID] 
[18] Roemmele M, Messman-Moore TL. Child abuse, early maladaptive schemas, and risky sexual behavior in college women. Journal of Child Sexual Abuse. 2011; 20(3):264-83. [DOI:10.1080/1053871 2.2011.575445] [PMID]

[19] Sundag J, Zens C, Ascone L, Thome S, Lincoln TM. Are schemas passed on? A study on the association between early maladaptive schemas in parents and their offspring and the putative translating mechanisms. Behavioural and Cognitive Psychotherapy. 2018; 46(6):738-53. [DOI:10.1017/S1352465818000073] [PMID]

[20] Khosravani V, Mehdizadeh A, Dortaj A, Alvani A, Amirinezhad A. Early maladaptive schemas, behavioral inhibition/approach systems, and defense styles in the abusers of opiate, stimulant, and cannabis drugs and healthy subjects. Journal of Substance Use. 2017; 22(3):317-23. [DOI:10.1080/14659891.2016.1208776] 